\title{
Cushing's Syndrome: An ominous and commonly forgotten cause of hypokalemia
}

\author{
Seow $\mathrm{CJ}^{1}$, Ng ZG ${ }^{1}, \mathrm{CML}_{\mathrm{Teo}}{ }^{1}$, Lum ${ }^{1}$, Chow M${ }^{1}$, Ong CE${ }^{1}$, Lai R ${ }^{1}$, Ryanputra $\mathrm{D}^{2}$ \\ ${ }^{1}$ Department of Endocrinology, Tan Tock Seng Hospital, Singapore \\ ${ }^{2}$ Yong Loo Lin School of Medicine, National University of Singapore, Singapore
}

\section{BACKGROUND}

Cortisol excess, via saturation of 11-beta-hydroxysteroid dehydrogenase type 2 at the renal tubule, exhibits mineralocorticoid activity and results in hypokalemic alkalosis. We report a patient with hypokalemia secondary to Cushing's Syndrome (CS) to reinforce this commonly forgotten association.

\section{CASE DESCRIPTION}

A 57 year-old lady with newly diagnosed hypertension, hyperlipidemia and diabetes mellitus presented with persistent hypokalemia for evaluation. She had tinea corporis but otherwise did not appear Cushingoid. Investigations (Table 1): $\mathrm{K}^{+} 2.6$ (RI: $\left.3.50-5 \mathrm{mmol} / \mathrm{L}\right)$, $\mathrm{HCO}_{3}$ 35 (RI: 19-31 mmol/L), Urine $\mathrm{K}^{+} / \mathrm{Cr} 8.1$. Both renin and aldosterone were suppressed. 24 hour urinary free cortisol (UFC) was elevated at 1811 (RI: $59-413 \mathrm{nmol} / \mathrm{day}) ; 8 \mathrm{am}$ cortisol after $1 \mathrm{mg}$ overnight dexamethasone suppression test (ONDST) was elevated at $1156 \mathrm{nmol} / \mathrm{L}$. The patient denied taking any licorice or corticosteroids. ACTH dependent CS was made with ACTH level of $12.1 \mathrm{pmol} / \mathrm{L}$. Overnight $8 \mathrm{mg}$ DST suppressed the cortisol to more than $50 \%(1223 \mathrm{nmol} / \mathrm{L} \rightarrow 351 \mathrm{nmol} / \mathrm{L})$. Magnetic Resonance Imaging (MRI) of the pituitary gland (Figure 1) revealed an expansile lesion involving the central skull base-sella and clivus, measuring $3.8 \times 3.0 \times 2.3 \mathrm{~cm}$. It encases the pituitary gland and displaces both the gland and the stalk toward the right. There is also encasement of the intracavernous left internal carotid artery (ICA) and the mass is also seen wrapping around the medial aspect of the right intracavernous ICA. Chordoma is a likely differential for this neoplastic lesion. Bilateral Inferior Petrosal Sinus Sampling (BIPSS) was not performed as interpretation may be difficult given the proximity of the lesion to the pituitary gland. She was promptly referred to the neurosurgeon for surgery.

\section{INVESTIGATIONS}

\begin{tabular}{|c|c|c|}
\hline Test & $\underline{\text { Results }}$ & Reference Range \\
\hline $\mathrm{K}+$ & 2.6 & $3.5-5 \mathrm{mmol} / \mathrm{L}$ \\
\hline HCO3- & 35 & $19-31 \mathrm{mmol} / \mathrm{L}$ \\
\hline Urine K/Cr & 8.1 & Renal Loss $>1.5$ \\
\hline Aldosterone & \multicolumn{2}{|c|}{$47 \mathrm{pmol} / \mathrm{L}$} \\
\hline Renin & \multicolumn{2}{|c|}{$<0.13 \mathrm{ng} / \mathrm{ml} / \mathrm{hr}$} \\
\hline ACTH & \multicolumn{2}{|c|}{$12.1 \mathrm{pmol} / \mathrm{L}$} \\
\hline 24 hour UFC & 1811 & $59-413 \mathrm{nmol} /$ day \\
\hline $1 \mathrm{mg}$ ONDST & 1156 & $<50 \mathrm{nmol} / \mathrm{L}$ \\
\hline $8 \mathrm{mg}$ ONDST & \multicolumn{2}{|c|}{$1223 \mathrm{nmol} / \mathrm{L} \rightarrow 351 \mathrm{nmol} / \mathrm{L}$} \\
& (more than $50 \%$ suppression) \\
\hline BMD & T-score -3.3 at Lumbar spine and -3.0 at femoral \\
& \multicolumn{2}{|c|}{ neck } \\
\hline
\end{tabular}

Table 1: Results of investigations

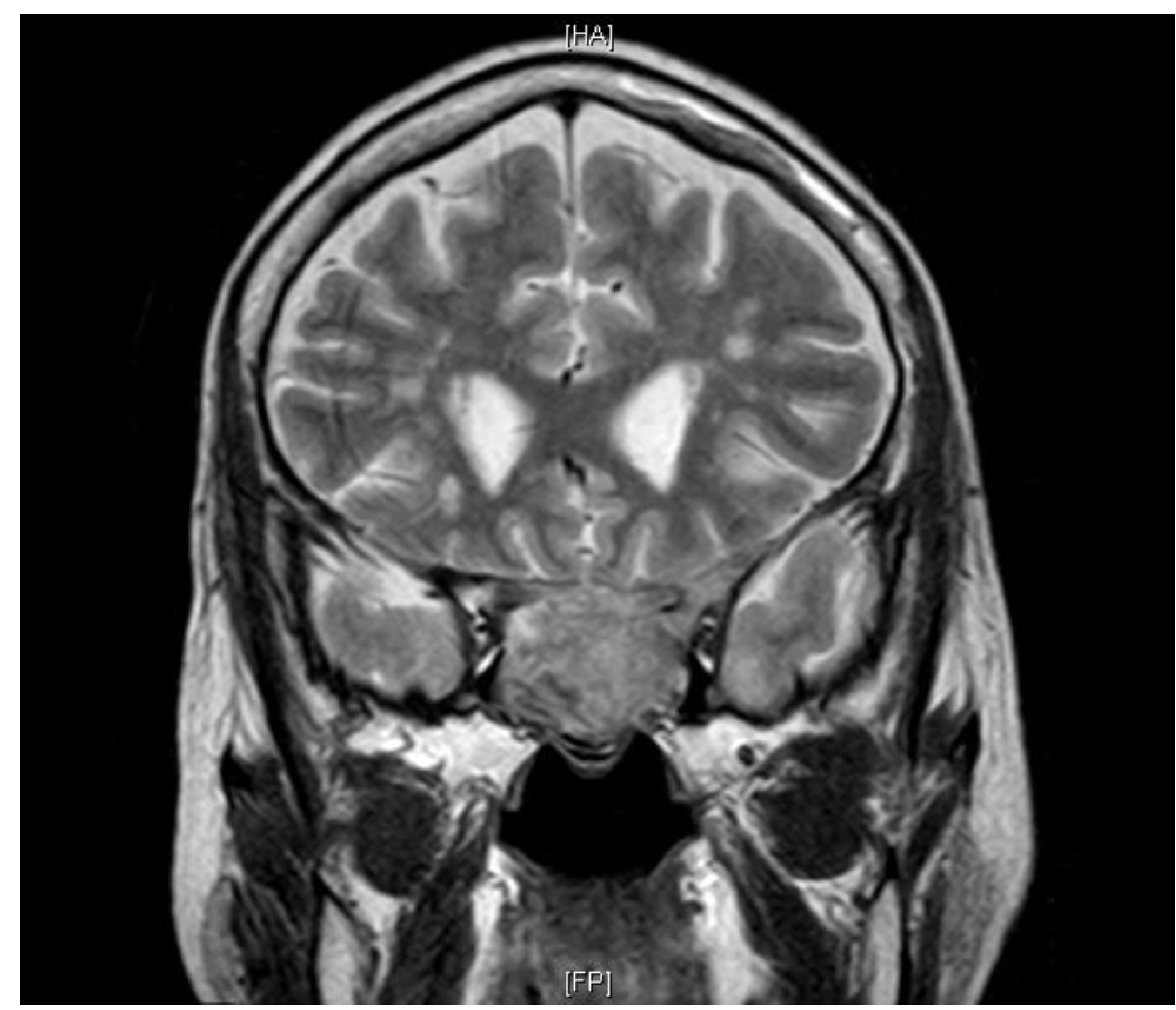

Figure 1: MRI of the pituitary gland showing the expansile lesion involving the central skull base-sella and clivus.

\section{DISCUSSION}

Activation of mineralocorticoid (MC) receptors by cortisol is normally limited due to its conversion to inactive cortisone at the sites of aldosterone action by the enzyme 11-beta-hydroxysteroid dehydrogenase type 2 (11-beta-HSD2). In ACTH-dependent CS, cortisol secretion exceeds the metabolic capacity of 11-betaHSD2. ACTH inhibits 11-beta-HSD2 and there may also be hypersecretion of nonaldosterone mineralocorticoids such as deoxycorticosterone (DOC) and corticosterone. Excess MC activity leads to sodium retention, hypertension, hypokalemia, metabolic alkalosis, low plasma aldosterone and renin activity. Besides CS, other differentials to consider include 11-beta-HSD2 deficiency, licorice ingestion, Liddle's Syndrome, DOC-secreting tumour and certain forms of congenital adrenal hyperplasia.

\section{CONCLUSION}

It is important to increase awareness of the association between Cushing Syndrome and hypokalemia. Earlier diagnosis and management may improve outcome. 